\title{
METODE ARIMA UNTUK MEMODELKAN VOLUME PRODUKSI KELAPA SAWIT PADA PT. SOCFINDO DI KABUPATEN ACEH TAMIANG
}

\author{
Wiwin Apriani' ${ }^{1}$ Rahmi Hayati ${ }^{2}$ \\ 1,2 Universitas Almuslim, Bireun, Aceh \\ wiwina10@gmail.com
}

\begin{abstract}
This study aims to create a mathematical model that can be used to predict the amount of oil palm that will be produced at PT. Socfindo in Aceh Tamiang Regency in the coming period. The data used is data on the amount of oil palm that is ready to be produced every month in 2012-2015. The method used is the ARIMA method. The selection of this method is based on the data used, namely time series data. Before carrying out further testing, first, ensure that the data used meets the stationary state. From the test results, it is found that the data used fulfills the stationary state, then it is found that the MA (1) model can be used to predict the time series data. Furthermore, we obtain a model that can be used to predict the volume of oil palm production at PT. Socfindo is:
\end{abstract}

$Z_{t}=a_{t}-0,4096 a_{t-1}+521,57$ with $a_{t} \sim N(0 ; 29192,72)$.

Keywords: ARIMA, Forecasting, Stationarity, Production volume

\begin{abstract}
ABSTRAK Penelitian ini bertujuan untuk membuat suatu model matematika yang dapat digunakan untuk meramalkan banyaknya kelapa sawit yang akan di produksi pada PT. Socfindo di Kabupaten Aceh Tamiang pada periode yang akan datang. Adapun data yang digunakan adalah data banyaknya kelapa sawit yang siap untuk di produksi setiap bulan pada tahun 2012-2015. Adapun metode yang digunakan adalah Metode ARIMA. Pemilihan Metode ini berdasarkan pada data yang digunakan yaitu data deret waktu. Sebelum melakukan pengujian lebih lanjut, terlebih dahulu dipastikan bahwa data yang digunakan memenuhi keadaan stasioner. Dari hasil pengujian diperoleh bahwa data yang digunakan memenuhi keadaan stasioner, kemudian diperoleh bahwa model MA(1) dapat digunakan untuk meramalkan data deret waktu tersebut. Selanjutnya diperoleh model yang dapat digunakan untuk meramalkan volume produksi kelapa sawit di PT. Socfindo adalah:
\end{abstract}

$Z_{t}=a_{t}-0,4096 a_{t-1}+521,57$ dengan $a_{t} \sim N(0 ; 29192,72)$.

Kata-kata Kunci : ARIMA, Peramalan, Stasioneritas, Volume produksi

\section{PENDAHULUAN}

Indonesia sebagai salah satu negara agraris yang sebagaian besar penduduknya bermata pencarian pada sektor pertanian. Sedangkan pada sektor perkebunan, Indonesia memiliki komoditas unggulan yaitu kelapa sawit. Hasil olahan dari kelapa sawit adalah minyak kelapa sawit atau yang di sebut dengan Crude Palm Oil (CPO) (Nurmalita, 2018). Menurut Maygirtasari (2015) Indonesia merupakan negara yang kaya akan Sumber Daya Alam dan Sumber Daya Manusia. Sumber Daya Alam yang melimpah dijadikan sebagai sumber tanaman pangan dan komoditas ekspor. 
Perkebunan merupakan salah satu subsektor yang memiliki peran penting dalam pembangunan, salah satu nya perkebunan kelapa sawit. Kelapa sawit adalah tumbuhan yang menghasilkan minyak masak, minyak industri maupun bahan bakar. Bagian terpenting dari kelapa sawit adalah buahnya yang dapat menghasilkan minyak kelapa sawit mentah yang diolah menjadi minyak goreng. Minyak kelapa sawit adalah bahan baku utama pembuatan minyak goreng. Minyak kelapa sawit merupakan salah satu komoditas unggulan ekspor Indonesia (Alatas, 2015). Menurut Radifan (2014) produksi Kelapa sawit di Indonesia yang besar menjadikan Indonesia sebagai salah satu negara pengekspor kelapa sawit terbesar. Menurut Carter et. al, (2007), pertumbuhan produksi minyak kelapa sawit Indonesia dalam beberapa tahun terakhir terus mengalami peningkatan. Indonesia mendominasi ekspor kelapa sawit dunia. Menurut Nirwana dalam penelitian Radifan (2014) yang dimaksud dengan produksi ialah hubungan fungsional antara hasil produksi atau disebut dengan output dengan faktor produksi atau disebut dengan input (tenaga kerja, modal, bahan baku dan sebagainya.

Untuk mendapatkan informasi pertumbuhan volume produksi, tidak cukup hanya dengan mengandalkan informasi volume produksi saat ini saja. Informasi volume produksi dari masa lalu harus juga diketahui. Dari informasi-informasi inilah yang nantinya dapat membuat sebuah metode yang mampu menggambarkan bagaimana laju volume produksi tersebut dan informasi dari laju volume produksi itu dapat terbentuk sedemikian rupa sampai dengan informasi laju volume produksi pada saat ini. Dengan menggunakan metode ARIMA informasi laju volume produksi dapat diramalkan. Hal inilah yang disebut dengan peramalan time-series (time-series forecasting). Peramalan time series merupakan suatu metode analisis data yang ditujukan untuk melakukan suatu estimasi maupun peramalan pada masa yang akan datang (Makridakis, Wheelwright \& McGee, 2002). Dalam peramalan time series dapat diketahui bagaimana proses suatu estimasi dan hasil dari peramalan dapat diperoleh dengan baik. Untuk itu dalam analisis ini dibutuhkan berbagai macam informasi atau data yang cukup banyak dan diamati dalam periode waktu yang relatif cukup panjang. Untuk mendapatkan informasi-informasi yang dibutuhkan mengenai laju volume produksi tersebut, metode yang digunakan adalah Autoregressive Integrated Moving Average (ARIMA), karena pada metode ARIMA merupakan suatu statistik yang cocok digunakan untuk meramal sejumlah variabel secara cepat, sederhana, murah, dan akurat karena hanya membutuhkan data variabel yang akan diramal. Metode ARIMA menggunakan pendekatan iteratif dalam indentifikasi terhadap suatu model yang ada. Model yang dipilih dan diuji dengan data masa lampau untuk melihat apakah model tersebut menggambarkan keadaan data secara akurat atau tidak.

Model AutoRegressive Integrated Moving Average (ARIMA) atau model gabungan auto-regresi dengan rata-rata bergerak, adalah jenis model linier yang mampu mewakili deret waktu yang stasioner maupun non-stasioner. Pada metode peramalan dengan menggunakan metode ARIMA (Autoregressive Integrated MovingAverage), di mana sangat baik ketepatannya untuk peramalan jangka 
pendek, sedangkan untuk peramalan jangka panjang ketepatan peramalannya kurang baik. Biasanya akan cenderung flat (mendatar/konstan) untuk periode jangka panjang. Model ARIMA adalah model yang secara penuh mengabaikan independen variabel dalam membuat peramalan. ARIMA menggunakan data

Peneliti-peneliti terdahulu yang telah dilakukan diantaranya oleh Abidin (2008) menganalisis ekspor minyak kelapa sawit (CPO) Indonesia dengan menggunakan regresi linier berganda $2 \mathrm{OLS}$ (two Stage Square) dengan metode OLS berdasarkan data time series 1996-2005. Selanjutnya Pimpi (2013) meneiliti tentang menerapkan metode ARIMA dalam meramalkan Indeks Harga Konsumen (IHK). Selanjutnya Ruslan (2013) melakukan peramalan nilai ekspor di Propinsi Sumatera Utara dengan metode ARIMA Box-Jenskin. Hasil penelitian pimpi dan ruslan menyatakan bahwa metode ARIMA merupakan suatu metode yang efektif dan akurat untuk melakukan peramalan data time series. Namun belum ada penelitian yang meramalkan laju volume produksi kelapa sawit di Aceh Tamiang dengan menggunakan metode ARIMA. Oleh karena itu, penelitian ini bertujuan untuk melakukan peramalan laju volume produksi kelapa sawit di Aceh Tamiang menggunakan metode ARIMA.

\section{METODE PENELITIAN}

Penelitian ini merupakan penelitian kuantitatif dengan metode deskriptif yang bertujuan mengungkap suatu data apa adanya berdasarkan fakta yang dimiliki. Menurut Arikunto (2006), penelitian kuantitatif, banyak dituntut menggunakan angka mulai dari pengumpulan data, menafsirkan data, serta menyajikan data tersebut sesuai hasil yang diinginkan. Sehingga dapat disimpulkan bahwa penelitian deskriptif kuantitatif pada penelitian ini untuk meramalkan dan mendeskripsikan volume produksi kelapa sawit priode mendatang berdasarkan data yang dimiliki pada priode masa lalu PT. Socfindo. Data yang digunakan ialah data sekunder yaitu data hasil laporan banyak nya kelapa sawit yang siap untuk diproduksi setiap bulan di PT. socfindo Kabupaten Aceh Tamiang. Adapun data yang digunakan adalah sebagai berikut:

Tabel 1. Data volume produksi kelapa sawit

\begin{tabular}{cccccccc}
\hline \multicolumn{2}{c}{2012} & \multicolumn{2}{c}{2013} & \multicolumn{2}{c}{2014} & \multicolumn{2}{c}{2015} \\
\hline $\begin{array}{c}\text { Data } \\
\text { Ke- }\end{array}$ & $\begin{array}{c}\text { Volume } \\
\text { Produksi } \\
\text { (Ton) }\end{array}$ & $\begin{array}{c}\text { Data } \\
\text { Ke- }\end{array}$ & $\begin{array}{c}\text { Volume } \\
\text { Produksi } \\
\text { (Ton) }\end{array}$ & $\begin{array}{c}\text { Data } \\
\text { Ke- }\end{array}$ & $\begin{array}{c}\text { Volume } \\
\text { Produksi } \\
\text { (Ton) }\end{array}$ & $\begin{array}{c}\text { Data } \\
\text { Ke- }\end{array}$ & $\begin{array}{c}\text { Volume } \\
\text { Produksi } \\
\text { (Ton) }\end{array}$ \\
\hline 1 & 600 & 13 & 500 & 25 & 340 & 37 & 550 \\
2 & 450 & 14 & 400 & 26 & 150 & 38 & 500 \\
3 & 300 & 15 & 450 & 27 & 550 & 39 & 500 \\
4 & 500 & 16 & 400 & 28 & 500 & 40 & 370 \\
5 & 400 & 17 & 350 & 29 & 600 & 41 & 560 \\
6 & 550 & 18 & 400 & 30 & 600 & 42 & 450 \\
7 & 300 & 19 & 450 & 31 & 350 & 43 & 300 \\
8 & 250 & 20 & 450 & 32 & 800 & 44 & 245 \\
9 & 750 & 21 & 550 & 33 & 850 & 45 & 400 \\
10 & 850 & 22 & 250 & 34 & 600 & 46 & 750
\end{tabular}




\begin{tabular}{cccccccc}
\hline \multicolumn{2}{c}{2012} & \multicolumn{2}{c}{2013} & \multicolumn{2}{c}{2014} & \multicolumn{2}{c}{2015} \\
\hline $\begin{array}{c}\text { Data } \\
\text { Ke- }\end{array}$ & $\begin{array}{c}\text { Volume } \\
\text { Produksi } \\
\text { (Ton) }\end{array}$ & $\begin{array}{c}\text { Data } \\
\text { Ke- }\end{array}$ & $\begin{array}{c}\text { Volume } \\
\text { Produksi } \\
\text { (Ton) }\end{array}$ & $\begin{array}{c}\text { Data } \\
\text { Ke- }\end{array}$ & $\begin{array}{c}\text { Volume } \\
\text { Produksi } \\
\text { (Ton) }\end{array}$ & $\begin{array}{c}\text { Data } \\
\text { Ke- }\end{array}$ & $\begin{array}{c}\text { Volume } \\
\text { Produksi } \\
\text { (Ton) }\end{array}$ \\
\hline 11 & 675 & 23 & 850 & 35 & 800 & 47 & 900 \\
12 & 500 & 24 & 650 & 36 & 650 & 48 & 800 \\
\hline
\end{tabular}

Tabel 1 diatas merupakan data volume produksi kelapa sawit tiap bulan, mulai dari januari 2012 sampai dengan desember 2015. Adapun teknik pengumpulan data yaitu teknik dokumentasi atau studi pustaka, dimana data yang diperoleh berdasarkan hasil laporan tiap bulanan yang telah diterbitkan oleh PT. Socfindo pada priode 2012 - 2015. Pada penelitian ini menggunakan instrumen berupa catatan berkala hasil laporan volume penjualan kelapa sawit pada tiap bulan yang dimiliki PT. Socfindo. Adapun data yang diperoleh selanjutnya digunakan untuk meramalkan volume produksi kelapa sawit di PT. Socfindo dengan menggunakan model ARIMA.

Model ARIMA (Autoregressive Integrated Moving Average) dikembangkan oleh George Box dan GwilynJenkins (1976). Sehingga model ini bisa disebut sebagai model Box Jenkins. Model ARIMA merupakangabungan antara autoregressive (AR)dan moving average (MA), dimana model inimampu mewakili deret waktu yang stasionerdan non-stasioner (Arthur, dkk, 2000). Notasi umum dari model ARIMA adalah

$\operatorname{ARIMA}(p, d, q)$,

p merupakan model auto-regresif order-p yang mempunyai bentuk :

$$
Y_{t}=\theta_{0}+\theta_{1} Y_{t-1}+\theta_{2} Y_{t-2}+\cdots+\theta_{p} Y_{t-p}+\varepsilon_{t}
$$

Di mana :

$Y \dagger=$ Variabel respon (terikat) pada waktu $t$

$Y t-1, Y t-2, \ldots, Y t-p=$ Variabel respon pada masing-masing selang waktu $t-1, t-2, \ldots, t-$ $\mathrm{P}$

$Y=$ variabel bebas

$\theta_{0}, \theta_{1}, \theta_{2}, \ldots, \theta_{p}=$ Koefisien yang diestimasi

$\varepsilon_{\dagger}=$ Galat pada saat $\dagger$ yang mewakili dampak variabel-variabel yang tidak dijelaskan oleh model

Asumsi mengenai galat adalah sama dengan asumsi model regresi standar. D merupakan banyaknya selisih yang didapat dari proses penyisihan (differencing) dari deret waktu yang non-stasioner menjadi deret waktu stasioner. Jika deret aslinya stasioner, $d=0$ model ARIMA berubah menjadi model ARMA. Persamaan dari proses penyisihan (differencing $d$ ) yaitu $\Delta Y_{t}=Y_{t}-Y_{t-1}$.

q merupakan model rata-rata bergerak orde ke $q$ yang mempunyai bentuk:

di mana :

$$
Y_{t}=\mu+\varepsilon_{t}-\omega_{1} \varepsilon_{t-1}-\omega_{2} \varepsilon_{t-2}-\cdots-\omega_{q} \varepsilon_{t-q}
$$

$Y \dagger=$ Variabel respon (terikat) pada saat $\dagger$

$\mu=$ Mean konstanta proses

$\omega 1, \omega 2, \ldots, \omega q=$ Koefisien yang diestimasi 
$\varepsilon t=$ Bentuk galat yang mewakili efek variabeltak terjelaskan oleh model.

Asumsi mengenaibentuk galat adalah sama dengan asumsimodel regresi standar. $\varepsilon t-$ $1, \varepsilon t-2, \ldots, \varepsilon t-q$ merupakan galat pada periode waktusebelumnya yang pada saat $t$, nilainyamenyatu dengan nilai respon $Y$ t. Sebelum membentuk sebuah modelARIMA pada suatu deret waktu maka harusdilakukan 4 proses yang dijalankan yaitu :

1. Mengidentifikasi Model dan ujistasioneritas terhadap data deret waktu volume penjualan kelapa sawit. Uji stasioneritas digunakan untuk mengetahui apakah deret waktu berbentuk stasioner atau nonstasioner.

2. Mengestimasi dari model yang terbentuk.

3. Memeriksa model dengan menggunakan nilai $Q$ Box-Pierce

4. Peramalan terhadap model untuk lima periode kedepan.

\section{HASIL DAN PEMBAHASAN}

\section{Uji Stasioneritas dan Identifikasi Model}

Untuk pengujian stasioneritas dapat dilihat pada Gambar 1. Pada grafik tersebut terlihat bahwa rata-rata dan varias dari data tersebut adalah konstan, sehingga dapat disimpulkan bahwa data tersebut adalah stasioner.

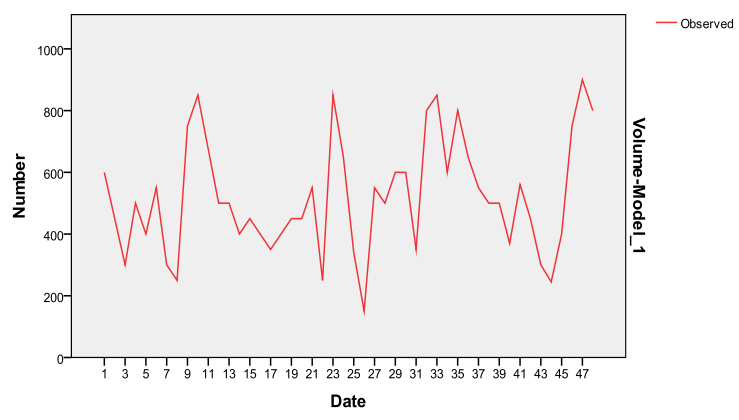

Gambar 1. Grafik Stasioner Volume Produksi Kelapa Sawit

\section{Identifikasi Model}

Setelah diperoleh data stasioner, langkah selanjutnya adalah melakukan identifikasi model dengan membandingkan FAK dan FAKP dari data dengan FAK dan FAKP teoritis. Adapun hasil pengolahan data dengan menggunakan MINITAB diperoleh FAK dan FAKP sebagai berikut:

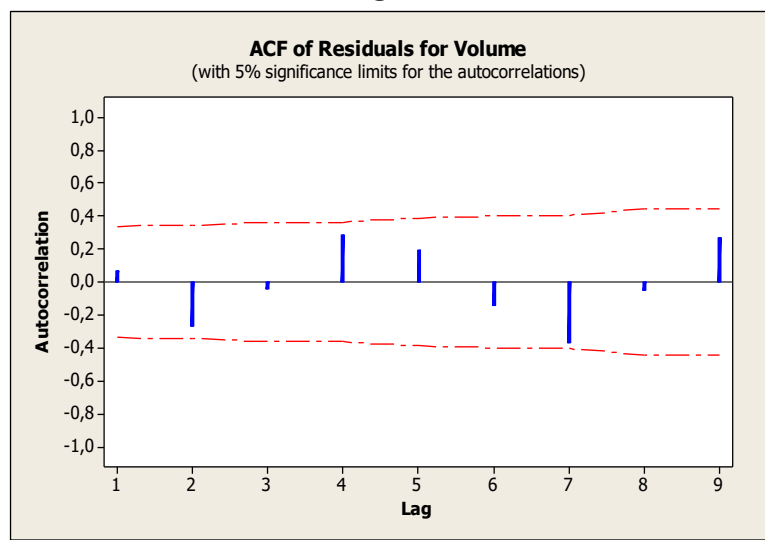

Gambar 2. Grafik FAK Volume Produksi Kelapa Sawit 


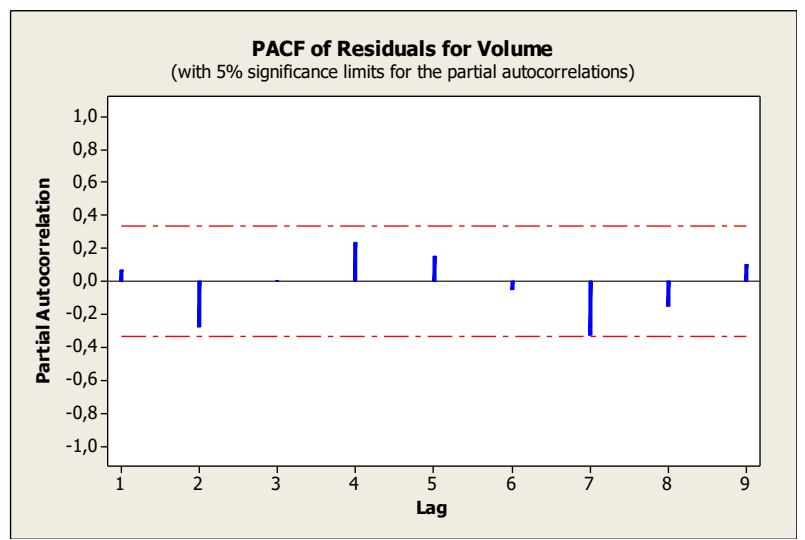

Gambar 3. Grafik FAKP Volume Produksi Kelapa Sawit

Berdasarkan FAK dan FAKP diatas, maka dapat diidentifikasi beberapa model yaitu $\operatorname{AR}(1), M A(1)$, dan ARMA $(1,1)$.

\section{Estimasi Parameter}

Setelah diperoleh model sementara, selanjutnya mencari penaksiran terbaik untuk parameter model tersebut. Hasil penaksiran data deret waktu tersebut dengan menggunakan Minitab adalah sebagai berikut:

\section{ARIMA Model: Volume}

Estimates at each iteration

Iteration SSE Parameters

$015170450,100467,715$

$1 \quad 14261280,250390,782$

$214029520,366331,615$

$314028580,373 \quad 328,546$

$\begin{array}{lllll}4 & 1402857 & 0,373 & 328,362\end{array}$

$\begin{array}{llll}5 & 1402857 & 0,373 \quad 328,350\end{array}$

Relative change in each estimate less than 0,0010

Final Estimates of Parameters

Type Coef SE Coef $T$ P

$\begin{array}{llllll}A R & 1 & 0,3733 & 0,1408 & 2,65 & 0,011\end{array}$

Constant 328,35 25,24 13,01 0,000

Mean $\quad 523,95 \quad 40,27$

Number of observations: 48

Residuals: $\quad$ SS $=1402163$ (backforecasts excluded)

$$
M S=30482 \mathrm{DF}=46
$$


Modified Box-Pierce (Ljung-Box) Chi-Square statistic

$\begin{array}{lllll}\text { Lag } \quad 12 \quad 24 \quad 36 & 48\end{array}$

Chi-Square $10,1 \quad 36,0 \quad 45,3$ *

DF $\quad 10 \quad 22 \quad 34 *$

P-Value $0,4320,0310,093 *$

\section{ARIMA Model: Volume}

Estimates at each iteration

Iteration SSE Parameters

$0 \quad 1745068 \quad 0,100 \quad 519,683$

$1 \quad 1562330-0,050 \quad 520,636$

$21441542-0,200 \quad 521,190$

$31379616-0,350 \quad 521,479$

$4 \quad 1373517-0,414 \quad 521,558$

$\begin{array}{llll}5 & 1373480 & -0,409 & 521,565\end{array}$

$61373480-0,410521,565$

Relative change in each estimate less than 0,0010

Final Estimates of Parameters

Type Coef SE Coef $T$ P

MA $1-0,40960,1348 \quad-3,04 \quad 0,004$

Constant $521,57 \quad 35,11 \quad 14,85 \quad 0,000$

Mean $\quad 521,57 \quad 35,11$

Number of observations: 48

Residuals: $\quad$ SS = 1372706 (backforecasts excluded)

$$
M S=29841 \text { DF }=46
$$

Modified Box-Pierce (Ljung-Box) Chi-Square statistic

$\begin{array}{lllll}\operatorname{Lag} \quad 12 \quad 24 \quad 36 & 48\end{array}$

Chi-Square $8,7 \quad 28,3 \quad 37,4 \quad *$

DF $\quad 10 \quad 22 \quad 34 *$

P-Value $0,5630,1640,316 *$

\section{ARIMA Model: Volume}

Estimates at each iteration

Iteration SSE Parameters

$\begin{array}{lllll}0 & 1615842 & 0,100 & 0,100 & 467,715\end{array}$

$1 \quad 14060940,250-0,050391,388$

$21386266 \quad 0,137-0,200 \quad 450,078$ 


$\begin{array}{lllll}3 & 1373177 & 0,044 & -0,350 & 498,477 \\ 4 & 1371757 & 0,079 & -0,345 & 480,590 \\ 5 & 1371752 & 0,081 & -0,346 & 479,907 \\ 6 & 1371752 & 0,081 & -0,346 & 479,801 \\ 7 & 1371752 & 0,081 & -0,346 & 479,806\end{array}$

Relative change in each estimate less than 0,0010

Final Estimates of Parameters

Type Coef SE Coef T P

$\begin{array}{llllll}\text { AR } & 1 & 0,0809 & 0,3677 & 0,22 & 0,827\end{array}$

$\begin{array}{llllll}\text { MA } 1 & -0,3456 & 0,3431 & -1,01 & 0,319\end{array}$

Constant $479,81 \quad 33,93 \quad 14,14 \quad 0,000$

Mean $\quad 522,02 \quad 36,91$

Number of observations: 48

Residuals: $\quad$ SS = 1370785 (backforecasts excluded)

$$
M S=30462 \mathrm{DF}=45
$$

Modified Box-Pierce (Ljung-Box) Chi-Square statistic

Lag $\quad 12 \quad 24 \quad 36 \quad 48$

Chi-Square $8,7 \quad 29,1 \quad 37,9 \quad *$

DF $\quad 9 \quad 21 \quad 33 *$

P-Value $0,4630,1120,256 *$

Dari perhitungan diatas diperoleh model AR(1) yang mempunyai bentuk $Z_{t}=\varphi Z_{t-1}+$ $a_{t}$ atau $\left(Z_{t}-\bar{Z}\right)=\varphi\left(Z_{t-1}-\bar{Z}\right)+a_{t}$. Dari hasil estimasi $\operatorname{AR}(1)$ diperoleh $\varphi=0,3733$. Karena mean $\bar{Z}=523,95>2$ SE $2(40,27)=80,54$, maka $\bar{Z}$ berbeda secara signifikan dengan nol. Sehingga model yang digunakan adalah model kedua. Sehingga diperoleh:

$$
Z_{t}=0,3733 Z_{t-1}+a_{t}+328,36
$$

Model MA(1) mempunyai bentuk $Z_{t}=a_{t}+\theta_{t-1}$ atau $\left(Z_{t}-\bar{Z}\right)=a_{t}+\theta a_{t-1}$. Dari hasil estimasi $M A(1)$ diperoleh $\theta=-0,4096$. Karena mean atau $\bar{Z}=521,57>2$ $\mathrm{SE}=2(35,11)=70,22$ maka $\bar{Z}$ berada secara signifikan dengan nol. Sehingga model yang digunakan adalah model bentuk kedua. Sehingga diperoleh:

$$
Z_{t}=a_{t}-0,4096 a_{t-1}+521,57
$$

Model ARMA $(1,1)$ mempunyai bentuk $Z_{t}=\varphi Z_{t-1}+a_{t}+\theta a_{t-1}$ atau $\left(Z_{t}-\bar{Z}\right)=\varphi\left(Z_{t-1}-\right.$ $\bar{Z})+a_{t}+\theta a_{t-1}$. Dari hasil ARMA diperoleh $\varphi=0,0809$ dan $\theta=-0,3456$. Karena mean atau $\bar{Z}=522,02>2 \mathrm{SE}=2(36,91)=73,82$ maka $\bar{Z}$ berada secara signifikan dengan nol. Sehingga model yang digunakan adalah model bentuk kedua. Sehingga diperoleh:

$$
Z_{t}=0,0809 Z_{t-1}+a_{t}-0,3456 a_{t-1}+479,79
$$




\section{Verifikasi Model}

a. Uji keberatian koefisien

Model AR(1)

$|\hat{\varphi}|=0,3733>2 S E=2(0,1408)=0,2816$

Jadi koefisien $\varphi$ berati berbeda secara signifikan dengan nol, hal ini berarti bahwa koefisien berarti.

Model MA(1)

$|\hat{\theta}|=0,4096>2 S E=2(0,1348)=0,2696$

Jadi koefisien $\theta$ berati berbeda secara signifikan dengan nol, hal ini berarti bahwa koefisien berarti.

Model ARMA $(1,1)$

$|\hat{\varphi}|=0,0809<2 S E=2(0,3677)=0,7354$

Jadi koefisien $\varphi$ berati tidak berbeda secara signifikan dengan nol, hal ini berarti bahwa koefisien tidak berarti.

$|\hat{\theta}|=0,3456<2 S E=2(0,3431)=0,6862$

Jadi koefisien $\theta$ berati tidak berbeda secara signifikan dengan nol, hal ini berarti bahwa koefisien tidak berarti.

Karena model ARMA tidak memenuhi dari segi keberartian koefisien, sehingga tidak perlu lagi diikut sertakan pada model selanjutnya.

b. Uji Kecocokan Model (Lack of Fit)

Uji kecocokan dilakukan untuk melihat kecocokan model dengan data. Adapun kriteria pengujian yang digunakan adalah model diterima jika P-value $>a$ dengan $a=0,05$.

Model AR(1)

Tabel 2 Nilai Q Box-Pierce Model AR(1) untuk Volume Produksi Kelapa Sawit

\begin{tabular}{|c|c|c|}
\hline LAG & P-Valve & Kesimpulan \\
\hline 12 & 0,432 & Model Sesuai \\
\hline 24 & 0,031 & $\begin{array}{c}\text { Model Tidak } \\
\text { Sesuai }\end{array}$ \\
\hline 36 & 0,093 & Model Sesuai \\
\hline
\end{tabular}

Model MA(1)

Tabel 3 Nilai Q Box-Pierce Model MA(1) untuk Volume Penjualan Kelapa Sawit

\begin{tabular}{ccc}
\hline LAG & P-Value & Kesimpulan \\
\hline 12 & 0,563 & Model Sesuai \\
24 & 0,164 & Model Sesuai \\
36 & 0,316 & Model Sesuai \\
\hline
\end{tabular}

Berdasarkan uraian diatas, maka model yang paling cocok dengan data adalah MA(1). Maka model peramalan untuk volume Produksi kelapa sawit adalah:

$$
Z_{t}=a_{t}-0,4096 a_{t-1}+521,57
$$

Dengan $a_{t} \sim N(0 ; 29192,72)$ 


\section{Peramalan}

Setelah didapat model yang sesuai dengan data volume produksi kelapa sawit, maka selanjutnya diperoleh ramalan volume produksi untuk 5 bulan kedepan adalah sebagai berikut:

Tabel 4 Data Aktual dan Data Peramalan Volume Produksi Kelapa Sawit dengan Model ARIMA

\begin{tabular}{ccc}
\hline $\begin{array}{c}\text { Data } \\
\text { Ke- }\end{array}$ & $\begin{array}{c}\text { Data } \\
\text { Aktual } \\
\text { (Ribu kg) }\end{array}$ & $\begin{array}{c}\text { Data Ramalan } \\
\text { (Ribu kg) }\end{array}$ \\
\hline 1 & 650 & 588,886 \\
2 & 550 & 521,565 \\
3 & 350 & 521,565 \\
4 & 625 & 521,565 \\
5 & 625 & 521,565 \\
\hline
\end{tabular}

\section{KESIMPULAN DAN SARAN}

Berdasarkan penelitian yang telah dilakukan diperoleh bahwa data volume produksi kelapa sawit membentuk deret waktu yang stasioner. Selanjutnya dari uji kecocokan model diperoleh bahwa model MA(1) yang cocok untuk meramalkan model volume penjualan kelapa sawit kedepannya. Adapun model yang diperoleh:

$$
Z_{t}=a_{t}-0,4096 a_{t-1}+521,57
$$

Dengan $a_{t} \sim N(0 ; 29192,72)$

\section{DAFTAR PUSTAKA}

Abidin Z. 2008. Analisis Ekspor Minyak Kelapa Sawit (CPO) Indonesia. Jurnal Aplikasi Manajemen, Vol. 6, No. 1, April 2008

Alatas, A. (2015). Trend Produksi dan Ekspor Minyak Sawit (CPO) Indonesia. Vol. 1. No. 2. hal. 114-124.

Carter, et. al. (2007). Palm Oil Markets and Future Supply. Europan Journal of Lipid Science and Technology. Vol. 109.No.4.

Makridakis, S., Wheelwright, S.C., \& McGee, V.E. (2002). Metode aplikasi dan peramalan. Jakarta. Binarupa Aksara Publisher.

Maygirtasari, Yulianto dan Mawardi. (2015). Faktor-Faktor Yang Mempengaruhi Volume Ekspor Crude Palm Oil (CPO) Indonesia. Jurnal Administrasi Bisnis. Vol. 25.No. 2.hal. 1-8.

Nurmalita, V, Wibowo, P.A. (2018). Analisis Faktor-Faktor yang Mempengaruhi Ekspor Minyak Kelapa Sawit Indonesia ke India. EEAJ 8 (2) (2018) 605-619

Pimpi, La. (2013). Penerapan metode ARIMA dalam meramalkan indeks harga konsumen (IHK) Indonesia Tahun 2013. Jurnal paradigma, Vol. 17; Hal. 35.

Radifan, Fakhrus. (2014). Faktor-Faktor Yang Mempengaruhi Ekspor Crude Palm Oil Indonesia Dalam Perdagangan Internasional. Economics Development Analysis Journal. Vol. 3.No. 2.hal. 259-267 
Ruslan, R.,Agus Salim Harahap., \& Pasukat Sembiring. (2013). Peramalan nilai ekspor di propinsi Sumatera Utara dengan metode ARIMA Box Jenkins. Jurnal saintia matematika, Vol. 1; Hal 579. 